\title{
Shift in cytotype frequency and niche space in the invasive plant Centaurea maculosa
}

\author{
Urs A. Treier, ${ }^{1,2,5}$ Olivier Broennimann, ${ }^{3}$ Signe Normand, ${ }^{2}$ Antoine Guisan, ${ }^{3}$ Urs Schaffner, ${ }^{4}$ \\ Thomas Steinger, ${ }^{1,6}$ And Heinz Müller-Schärer ${ }^{1}$ \\ ${ }^{1}$ Department of Biology, Unit of Ecology and Evolution, University of Fribourg, Chemin du Musée 10, CH-1700 Fribourg, Switzerland \\ ${ }^{2}$ Department of Biological Sciences, Systematic Botany, Aarhus University, Ny Munkegade 114, \\ Building 1540, DK-8000 Arhus C, Denmark \\ ${ }^{3}$ Department of Ecology and Evolution, University of Lausanne, The Biophore, CH-1015 Lausanne, Switzerland \\ ${ }^{4}$ CABI Europe-Switzerland, Rue des Grillons 1, CH-2800 Delémont, Switzerland
}

\begin{abstract}
Polyploidy is often assumed to increase the spread and thus the success of alien plant species, but few empirical studies exist. We tested this hypothesis with Centaurea maculosa Lam., a species native to Europe and introduced into North America approximately 120 years ago where it became highly invasive. We analyzed the ploidy level of more than 2000 plants from 93 native and 48 invasive $C$. maculosa populations and found a pronounced shift in the relative frequency of diploid and tetraploid cytotypes. In Europe diploid populations occur in higher frequencies than tetraploids and only four populations had both cytotypes, while in North America diploid plants were found in only one mixed population and thus tetraploids clearly dominated. Our results showed a pronounced shift in the climatic niche between tetraploid populations in the native and introduced range toward drier climate in North America and a similar albeit smaller shift between diploids and tetraploids in the native range. The field data indicate that diploids have a predominately monocarpic life cycle, while tetraploids are often polycarpic. Additionally, the polycarpic life-form seems to be more prevalent among tetraploids in the introduced range than among tetraploids in the native range. Our study suggests that both ploidy types of $C$. maculosa were introduced into North America, but tetraploids became the dominant cytotype with invasion. We suggest that the invasive success of $C$. maculosa is partly due to preadaptation of the tetraploid cytotype in Europe to drier climate and possibly further adaptation to these conditions in the introduced range. The potential for earlier and longer seed production associated with the polycarpic life cycle constitutes an additional factor that may have led to the dominance of tetraploids over diploids in the introduced range.
\end{abstract}

Key words: alien species; biogeography; biological invasion; Centaurea stoebe; ecological niche, ecological tolerance; flow cytometry; niche breadth; niche shift; ploidy; polyploidization; spotted knapweed.

\section{INTRODUCTION}

Several studies have tried to identify factors that make a species invasive (e.g., Blossey and Nötzold 1995, Mack et al. 2000, Keane and Crawley 2002, Callaway and Ridenour 2004) and because the proportion of polyploids is higher among invasive than among native species in some regional floras, several authors have recently suggested that polyploidy may constitute a favorable attribute for the success of alien plants (Verlaque et al. 2002, Pandit 2006, Pandit et al. 2006). Whether and why polyploids are more successful invaders remains unclear, however. Intuitively, the underlying mechanisms probably result from polyploidization leading to increased

\footnotetext{
${ }^{5}$ Present address: Department of Biological Sciences, Systematic Botany, Aarhus University, Ny Munkegade 114, Building 1540, DK-8000 Århus C, Denmark.

E-mail: urs.treier@gmail.com

${ }^{6}$ Present address: Agroscope Changins-Wädenswil ACW, CP 1012, CH-1260 Nyon, Switzerland.
}

and/or shifted ecological tolerance and altered functional traits including life history, herbivore resistance, selfincompatibility, and competitive ability (Levin 2002). Alternatively, shifts in cytotype frequency within individual taxa may simply result from stochastic processes (e.g., founder events) operating during range expansion (Kliber and Eckert 2005).

Evidence for increased ecological tolerance (niche breadth) of polyploids comes from Stebbins' (1971) observation that tetraploids tend to have larger geographic ranges than diploids. A comprehensive study including all taxa of the genus Clarkia reports that polyploid taxa have significantly larger ranges than diploid taxa (Lowry and Lester 2006). Furthermore, among invasive species polyploids were found to colonize a larger variety of habitats (Verlaque et al. 2002). Polyploids may not only have a broader niche, they may also differ in their niche optima, thus mainly occurring under environmental conditions that differ from those of their diploid conspecifics. For example Hagerup (1933) reported, besides a wider distribution of 
the tetraploid compared to the diploid Vaccinium uliginosum, distinct latitudinal and only slightly overlapping ranges between the two cytotypes. Similar differentiation between cytotypes was subsequently reported for various other diploid/polyploid complexes (e.g., Mosquin and Small 1971, Soltis and Soltis 1989, Van Dijk et al. 1992, Felber-Girard et al. 1996, Gauthier et al. 1998, Borgen and Hultgård 2003, Stuessy et al. 2004). In addition, Levin (2002) reports that polyploids, compared to their diploid conspecifics, can have an increased ability to tolerate stressful conditions such as low nutrient levels, drought, and cold temperatures.

When neopolyploids originate within diploid populations, an increased or shifted ecological tolerance may allow them to establish and propagate despite a potential fitness disadvantage resulting from incompatible matings with diploid plants (Levin 1975). Here we argue that niche differentiation in the native range may provide an explanation for the observed increased invasive success of polyploids compared to diploids (Verlaque et al. 2002, Pandit 2006, Pandit et al. 2006). Let us consider a situation in which environmental conditions in the introduced range differ from those in the native range. In this case, polyploids with increased ecological tolerance or a shifted niche optimum toward the environmental conditions in the introduced range are expected to have an advantage over diploids, because of a larger degree of niche overlap between the native and introduced range (i.e., polyploids are preadapted to ecological conditions in the introduced range). Furthermore, selection on traits responsible for the broader or shifted tolerance may further increase their fitness under the environmental conditions encountered in the new range (post-invasion evolution). Thus, due to preadaptation to these altered environmental conditions, polyploids will become the dominant cytotype in the introduced range and are expected to exhibit a shift in their niche optimum, compared to the combined niche of native diploids and polyploids. Furthermore their niche should be shifted in the same direction as the niche of the polyploids in the native range compared to the diploids.

An alternative mechanism for the increased invasive success of polyploids could be that they harbor traits providing them with an advantage when released from biotic constraints (e.g., specialist herbivores). Prolonged life span and polycarpy are commonly observed functional traits in polyploids. Compared with monocarpic biennials or perennials, prolonged life span and polycarpy may increase seed output through earlier and repeated reproduction but may also favor the buildup of higher herbivore loads (Lawton and Schroder 1977, Klinkhamer et al. 1997). For example, in Centaurea maculosa Lam., specialized root-feeding herbivores were found to attack and kill larger plants preferentially (Müller 1989b, Müller et al. 1989). Even though such higher loads of natural enemies may disadvantage polyploids in the native range, a predominantly peren- nial, polycarpic life cycle may favor polyploids in environments that lack such natural enemies, e.g., after transcontinental introductions or island colonization (Müller-Schärer et al. 2004). In line with this argument, a clear trend toward a polycarpic life-form and longer life span was observed for species on islands (Böhle et al. 1996). Following the same line of arguments as the evolution of increased competitive ability (EICA) hypothesis (Blossey and Nötzold 1995), polyploid genotypes that invest in repeated reproduction and thereby become more susceptible to natural enemies would be favored over diploid genotypes that escape natural enemies by investing only once in reproduction (Klinkhamer et al. 1997, Müller-Schärer et al. 2004). In this situation, in which release from biotic constraints is the main difference between the introduced and the native range, with environmental conditions otherwise being similar, polyploids are expected to become the dominant cytotype in the introduced range through earlier and repeated seed output. In contrast to the situation in which preadaptation to altered environmental conditions is important, here the niche of the polyploids in the introduced range should not differ from the combined niche of the diploids and polyploids in the native range, neither in terms of niche breadth nor in terms of niche optimum. We do not expect these two mechanisms to be mutually exclusive, and in fact, their joint action would reinforce the dominance of polyploids in the introduced range. Therefore, diploids may be very rare in the introduced range and are possibly, if still present, confined to small relict populations in areas of first successful introduction where climatic conditions are similar to those in the native range (cf. Broennimann et al. 2007).

In the present study we provide a comprehensive assessment of the geographic distribution of the two ploidy types of Centaurea maculosa across its native (Europe) and introduced (North America) ranges, to assess whether polyploids became the dominant cytotype during the invasion process and to unravel the potential underlying mechanisms as outlined above. Specifically we ask: (1) Do the cytotypes differ in their niche breadth or niche optima in the native range, and did the niche optimum further shift in the introduced range? (2) Does the niche of the polyploids in the introduced range differ from the combined niche of diploids and polyploids in the native range? (3) Do life history traits differ between cytotypes? By answering these questions we seek support for either one or both of the outlined mechanisms: preadaptation to altered environmental conditions or increased competitive ability through altered life-history traits as an explanation for the expected increased invasion success of polyploids.

\section{Methods \\ Study species}

Centaurea maculosa Lam. (syn. C. stoebe L.) is native to Europe, but a highly invasive plant species in North 
America, to where it was introduced 120 years ago (Roché et al. 1986). The taxonomy of C. maculosa is unclear (Ochsmann 2000, Royal Botanic Garden Edinburgh 2007) and presently under investigation. Ochsmann (2001) suggested subdividing the species according to the known ploidy levels: $C$. stoebe L. subsp. stoebe (diploid $2 n=18$ ) and $C$. stoebe L. subsp. micranthos (Gugler) Hayek (tetraploid $2 n=36$ ). It is currently not known if the tetraploid cytotype originated through auto- or allopolyploidization. In order to include the complete native range and to ensure robust crosscontinental comparison, we considered C. maculosa sensu lato (s.l.) as the taxonomic entity.

\section{Population data and environmental variables}

We used data from 97 populations collected during our own field surveys in 2005 as well as from 44 additional populations sampled by colleagues, resulting in a total sample size of 141 C. maculosa populations (Fig. 1, Appendix A). Overall, data from 93 and 48 populations were available from Europe (EU) and North America (NA), respectively.

The field surveys were performed by sampling populations spaced by at least $16 \mathrm{~km}$. Population sampling depended on the abundance of $C$. maculosa plants at each site: seeds from 16 randomly selected plants were sampled in populations with low abundance while plants were systematically sampled in populations with high abundance. Systematic sampling depended on the area covered by the population: we sampled 16 plants along a transect of $50 \times 2 \mathrm{~m}\left(100 \mathrm{~m}^{2}\right)$ or in two sub-transects $(\sim 25 \times 2 \mathrm{~m})$ if the spatial structure of the population did not allow sampling within one transect. Along the transect, 16 sampling points were defined, separated by $3 \mathrm{~m}$ and starting at $2.5 \mathrm{~m}$. In populations that covered only a small area not allowing transect sampling we defined 16 regularly spaced sampling points $(1.5 \mathrm{~m})$ across a square of $4.5 \times 4.5 \mathrm{~m}\left(20.25 \mathrm{~m}^{2}\right)$. At all sampling points, we selected the nearest $C$. maculosa plant. For each selected plant we collected seeds from at least 10 seed heads, measured plant height and mean diameter, counted the number of stems, noted whether the plant formed new lateral buds/shoots (an estimate of polycarpy), and scored herbivore damage (low, medium, or high) on different root parts (external, internal, and collar). If a selected plant did not carry seeds, we additionally chose the nearest fruiting plant for seed collection. We also estimated the area covered by the population in five classes $\left(<100 \mathrm{~m}^{2} ;<250 \mathrm{~m}^{2} ;<1000\right.$ $\mathrm{m}^{2} ;>1000 \mathrm{~m}^{2}$ but extend less than $1 \mathrm{~km}$; not determinable) and assessed population density by counting C. maculosa plants within an area of $20 \mathrm{~m}^{2}$ (in the transects every $5 \mathrm{~m}$ in a strip of $1 \times 2 \mathrm{~m}$ ) or 20.25 $\mathrm{m}^{2}$ (square sampling). We separately counted small and large rosettes as well as flowering plants and noted whether they formed new rosettes.

At each site we determined habitat type (forest, grassland, ruderal, waterside), the degree of anthropo- genic disturbance (low, medium, or high), slope, vegetation parameters (percentage of bare ground, grass and forb cover, mean grass and forb height), and various soil parameters ( $\mathrm{pH}$; Munsell Color [1975]: value, chroma; clay content; and presence of $\mathrm{CaCO}_{3}$, measured with an $\mathrm{HCl}$ reaction). In addition to the local field data, we used ArcGIS 9.0 (Environmental Systems Research Institute, Redlands, California, USA) to retrieve climate data for all populations (potential evapotranspiration, PET; ratio of actual to potential evapotranspiration, AET/PET; annual precipitation, PREC; annual variation in precipitation, STD_PREC; minimum temperature of the coldest months, TMIN; maximum temperature of the warmest months, TMAX; growing degree-days, GDD, defined as the sum of mean daily temperatures above $5^{\circ} \mathrm{C}$; CRU $10^{\prime}$ data set; New et al. 2002), land cover classification (forest, woodland s.l., grassland, cropland, urban; Hansen et al. 2000), and vegetation structure (remote sensing tree and bare ground cover [rm_tree, rm_bare; "MOD44b" data set] and primary productivity determined at three different times in the season from normalized difference vegetation indices [ndvi-3/22/05, ndvi-6/10/05, and ndvi9/30/05; "MOD13q1v4" data set] data sets available online). ${ }^{7}$ See Appendix B for more details on the environmental variables.

\section{Ploidy determination}

We attempted to grow one offspring from each individually collected plant per population (in general 16 , but available plants varied from 2 to 18 ). We also attempted to grow 16 plants if only population bulk seed samples were available. We successfully grew 2005 plants, on average 14 per population, from which the DNA ploidy level was estimated using flow cytometry (for population details and number of plants analyzed, see Appendix A). Populations were randomized and ploidy levels were determined with bulk samples. We only analyzed individual plants when both cytotypes were detected within a sample, thus for populations with mixed ploidy levels. In pretrials we determined that analyses of bulk samples with eight plants still allowed us to easily detect mixed ploidy levels within a sample. Samples were prepared in a petri dish by chopping 0.2 $\mathrm{cm}^{2}$ leaf tissue from eight plants for $30 \mathrm{~s}$ with a sharp razor blade in $500 \mu \mathrm{L}$ of extraction buffer (Partec, Münster, Germany). Thereafter, $500 \mu \mathrm{L}$ of extraction buffer was added. The mix was incubated for $\sim 1 \mathrm{~min}$ before filtering the nuclei suspension with a $30-\mu \mathrm{m}$ CellTrics disposable filter (Partec). Two milliliters of staining buffer (Partec; containing $20 \mu \mathrm{g}$ RNAse) were added, and the mix was incubated for at least $30 \mathrm{~min}$ in darkness. We analyzed the extracted and stained nuclei with a CyFlow SL Green 2P (CY-S-1022 HR, Partec). Data acquisition and analysis were done with the

\footnotetext{
${ }^{7}\langle$ https://lpdaac.usgs.gov/ $\rangle$
} 

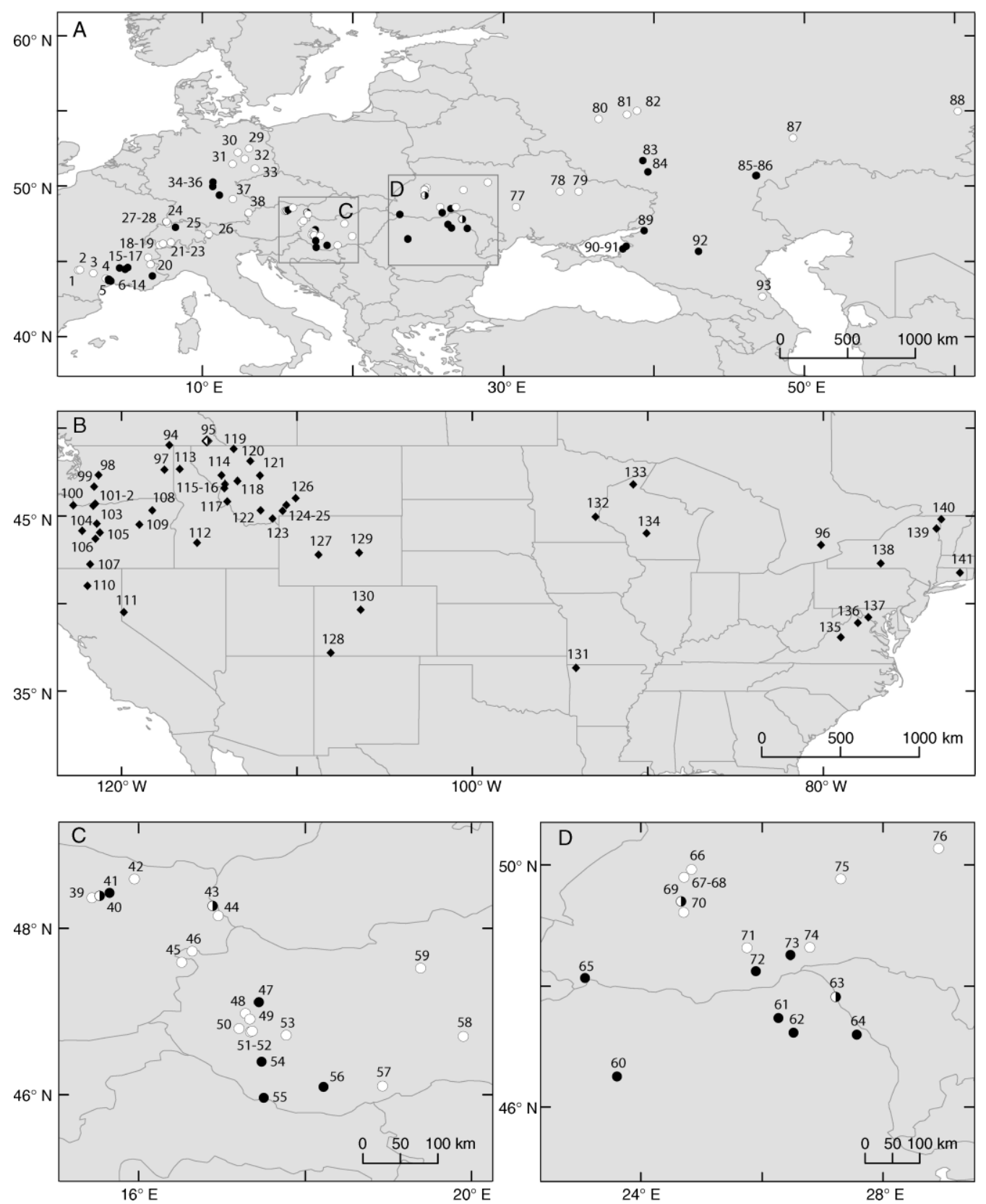

FIG. 1. Distribution of Centaurea maculosa sensu lato in its (A) native (Europe, circles) and (B) introduced (North America, diamonds) ranges. Open symbols indicate populations with diploid $(2 x)$ plants, solid symbols indicate populations with tetraploid $(4 x)$ plants, and half-filled symbols indicate populations with mixed occurrences. The enlargements (C, D) show areas in Europe where mixed populations occur. Note that the $4 x$ DNA ploidy level for populations in southern France is ambiguous. Exact locations of sampled populations (denoted by numbers associated with symbols) are given in Appendix A.

software FloMax version 2.0 (Quantum Analysis, Münster, Germany). The fluorescence intensity scale at position 100 was adjusted to a diploid plant of $C$. maculosa originating from population 44 (hereafter the standard plant). Samples of the standard plant were prepared as described above, except that more leaf tissue was used $\left(0.5 \mathrm{~cm}^{2}\right)$. Samples of the standard plant were then analyzed in regular intervals between the other samples and fluorescence peak position of sample peaks were compared to the mean peak position of the standard plant. We classified each population or individuals in mixed populations as diploid $(2 x)$ or tetraploid $(4 x)$ since DNA ploidy proved to be consistent with ploidy determined by chromosome counts (Bancheva and Greilhuber 2006). Up to now only chromosome numbers of $2 x=18$ and $4 x=36$ have 
been described for C. maculosa, but supernumerary B chromosomes may occur (Ochsmann 1999). Exact DNA contents were not assessed as this would have needed several independent measurements of individual plants to minimize measurement variation. Populations from southern France showed ambiguous $4 x$ DNA ploidy levels (indicated by smaller or intermediate genome size measurements; Fig. 1, Appendix A). All analyses were therefore performed with and without these populations. The results were in general consistent (see Appendix C), and we therefore reported the analyses including all populations, except when differences were obtained. Based on the combination of cytotype $(2 x / 4 x)$ and geographical range (Europe [EU]/North America [NA]), we assigned so-called geo-cytotypes $(2 x \mathrm{EU}, 4 x \mathrm{EU}$, $2 x \mathrm{NA}$, and $4 x \mathrm{NA}$ ) to each population for further analyses.

\section{Data analysis}

We tested for differences in niche optima (i.e., niche shifts) and niche breadth among geo-cytotypes using outlying mean index analysis (OMI; Doledec et al. 2000) and logistic regression (Hosmer and Lemeshow 2000). The OMI analysis is a constrained ordination method used to estimate species niche optimum and niche breadth (i.e., ecological tolerance) along environmental gradients (Doledec et al. 2000). In OMI analyses, niche optima are estimated as the difference between the mean climatic conditions under which a given species occurs and the mean climatic conditions of all studied sites (Doledec et al. 2000). In our analyses, geo-cytotypes were treated as "species" and assignment of populations in the analyses was weighted by geo-cytotype occurrence, i.e., 1 for purely diploid and tetraploid populations, and by observed cytotype ratio for mixed populations. Niche shifts, i.e., differences in niche optima among geo-cytotypes, were measured along the two OMI axes separately and in the OMI plane defined by those axes. Niche shifts were calculated as the Euclidian distance between the niche optima of geocytotypes, weighted by axis inertia. Niche breadth was calculated as the variance in the populations' position along the OMI axes (Thuiller et al. 2004, 2005) or as the ellipse surface in the OMI plane. The ellipses are a graphical summary of the cloud of points of each geocytotype, defined by the gravity center of the cloud (i.e., the midpoint) and 1.5 times the standard deviation of the projections of the points on the ellipse axis (drawn orthogonal with maximal dispersion). Differences in niche breadth among geo-cytotypes were calculated separately, as the difference between the variances on the two axes and in ellipse surface weighted by axes inertia. We used 999 Monte Carlo randomizations to test for differences in niche breadth (two-sided tests) and for niche shifts (one-sided tests). Using the OMI analysis we tested for niche shifts and differences in niche breadth along climatic, local-scale abiotic as well as large- and local-scale vegetation structure gradients (for variables see Appendix B). In addition, we tested whether geo-cytotypes differ in niche breadth by testing the difference in frequency of geo-cytotypes among habitat types with chi-square tests. Due to occurrences below the recommended minimum of five, we assessed the significance of the chi-square statistics by 9999 Monte Carlo randomizations (Sokal and Rohlf 1995).

We tried to disentangle the possible mechanisms causing niche shifts between geo-cytotypes in the two ranges with logistic regression models. Especially we examined whether differences in niche optima between cytotypes in the native range indicate preadaptation to the conditions in the introduced range. We ran the models with geo-cytotype contrasts $(2 x \mathrm{EU}$ vs. $4 x \mathrm{EU}$ and $4 x \mathrm{EU}$ vs. $4 x \mathrm{NA}$ ) as the response of one climatic or vegetation structure variable at a time. Testing for niche differentiation between $2 x \mathrm{EU}$ and $4 x \mathrm{EU}$ provides first evidence for preadaptation of the cytotype occurring closer to the conditions in the introduced range. In the case of a preadaptive advantage, however, we would expect this cytotype to further shift during invasion. Thus, testing for niche differentiation between $4 x \mathrm{EU}$ and $4 x$ NA provides additional support for preadaptation. Finally, logistic regression models built on the contrast between $2 x \mathrm{EU}$ and $4 x \mathrm{EU}$ and predicting the differences between $4 x \mathrm{EU}$ and $4 x \mathrm{NA}$ strengthen the evidence for preadaptation, by showing sequential shifts among the geo-cytotypes. The logistic regression analysis was performed with data splitting (70\% training and $30 \%$ test data) to assess model accuracy with the area under the curve (AUC) of the receiver-operating characteristic plots (Fielding and Bell 1997). Areaunder-the-curve values between 0.5 and 0.7 indicate no or poor discrimination, while values greater than 0.7 indicate reasonable discrimination between groups (Pearce and Ferrier 2000). We computed AUC values for 999 randomly split data sets to test whether a given model discriminated between groups (AUC $>0.5$ ). In addition, we calculated the conditional probability of correctly predicted geo-cytotypes, as the number of populations correctly assigned to a given geo-cytotype divided by all populations of this geo-cytotype (Fielding and Bell 1997).

To assess a possible link between geo-cytotypes and population traits, we performed nonparametric tests and analyses of variance (ANOVAs). Due to non-normality and unequal variance of several traits, we computed nonparametric Mann-Whitney $U$ tests to test for differences in the 15 population traits among ranges (native vs. introduced) and geo-cytotypes. We corrected $P$ values for multiple comparisons with the Dunn-Sidak method (Sokal and Rohlf 1995) and performed ANOVAs for traits for which transformations allowed the use of parametric statistics. As the results of ANOVAs and Mann-Whitney $U$ tests did not differ, only results from the latter are reported. Habitat disturbance is known to promote the spread and establishment of invasive species. We therefore used two-way factorial ANOVAs 
to test whether population averages of trait values between geo-cytotypes are altered by the level of anthropogenic disturbance.

ANOVAs and chi-square tests were performed in SPSS for Windows (release 12.0.1; SPSS, Chicago, Illinois, USA). Mann-Whitney $U$ tests, outlying mean index analysis (using the ade4 package: Dray and Dufour 2007), and logistic regressions were computed in the $\mathrm{R}$ environment (R Development Core Team 2007).

\section{RESULTS}

\section{Geographical distribution of cytotypes}

We determined the ploidy level of more than 2000 plants of $C$. maculosa originating from 141 natural populations spread across the whole geographical range. On average, we analyzed 13.7 individuals per population of the native range (Europe) and 15.2 individuals per population of the introduced range (North America). We observed a profound shift in the frequency of the two ploidy types between the native and introduced range, with $56 \%$ diploid, $40 \%$ tetraploid, and $4 \%$ mixed populations in Europe and $98 \%$ tetraploid and $2 \%$ mixed populations in North America (Fig. 1). No obvious geographical pattern in the distribution of the two ploidy cytotypes was observed except that they differed in the latitudinal occurrence at the European and global scale, with tetraploids being found at lower latitudes (medians, $2 x \mathrm{EU}=47.9^{\circ} \mathrm{N}, 4 x \mathrm{EU}=46.4^{\circ} \mathrm{N}$, $4 x \mathrm{EU}+\mathrm{NA}=45.6^{\circ} \mathrm{N}$; Mann-Whitney $U$ test, $P<$ 0.005 ). Overall, mixed populations were scarce (5 of 141 populations) and were therefore excluded from all except the OMI analyses. Three of the mixed populations were dominated by one ploidy type (1-2 plants of 14-16 of either the $2 x$ or $4 x$ cytotype) while more balanced frequencies $(37-50 \%)$ were found in the two other populations. The introduced range was dominated by tetraploid plants with only two diploid plants out of a total of 731 plants (Fig. 1; Appendix A). In summary, three main geo-cytotypes could be distinguished: native diploids ( $2 x \mathrm{EU})$, native tetraploids ( $4 x \mathrm{EU})$, and invasive tetraploids ( $4 x \mathrm{NA})$.

\section{Differences in niche optima among geo-cytotypes}

Cytotypes in the native range ( $2 x \mathrm{EU}$ vs. $4 x \mathrm{EU})$ only differed significantly in niche optima along the second OMI axis (Table 1), which represents a temperatureenergy gradient, indicating a shift of the EU tetraploids toward warmer climate (Fig. 2). At the local scale, tetraploids tended to occur preferentially on soils with higher $\mathrm{CaCO}_{3}$. Native and invasive tetraploids had significantly different niche optima along climatic gradients, large- and local-scale vegetation structure, and local abiotic gradients (Table 1). For local-scale and climatic gradients, we observed opposite shifts in niche optima between native and invasive tetraploids compared to the shifts between cytotypes in the native range. For soil factors, these trends were only observed when southern France populations, showing ambiguous $4 x$
DNA ploidy levels, were included in the analysis (cf. Appendix C). Results of additional OMI analyses testing for differences between the combined niche of native cytotypes and the niche of invasive tetraploids were very similar to the results for the comparison of native and invasive tetraploids (Table 1). We found highly significant niche shifts for all four gradients in the OMI plane and along axis 1, while axis 2 had no importance in these analyses. The OMI analyses indicate that invasive tetraploids tended to grow in areas with a more continental climate (drier with both higher and lower temperature extremes), more bare ground, and lower primary productivity. At the local scale, invasive tetraploids occurred more on soils with increased chroma values and lower $\mathrm{CaCO}_{3}$ contents as well as vegetation characterized by lower forb cover but higher mean forb and grass height. Logistic regression models showed that GDD, TMAX, and PET significantly discriminated between cytotypes in the native range. The models predicted $2 x \mathrm{EU}$ populations better than $4 x$ EU populations (Table 2). Tetraploids between ranges were significantly discriminated by AET/PET, GDD, PET, and TMIN; again, the models had lower prediction accuracy for the $4 x \mathrm{EU}$ populations (Table 2). Potential evapotranspiration and GDD predicted both the differences between cytotypes in Europe and between the tetraploids in the two ranges, but the latter with opposite signs. Models, which we calibrated on the two cytotypes in the native range, showed AET/PET and PET as best predictors for the observed niche shift between native and invasive tetraploids unraveling sequential shifts among geo-cytotypes (Table 2).

\section{Differences in niche breadth among geo-cytotypes}

Niche breadth (ecological tolerance) along large-scale vegetation structure gradients tended to increase from diploids to tetraploids in the native range and increased even further for tetraploids in the introduced range, as indicated by the OMI analyses (Table 1). At the local scale, ecological tolerance also tended to increase in native tetraploids but this trend clearly reversed for invasive tetraploids, which showed reduced niche breadth for local soil conditions (Table 1). Again, the overall contrast between the native and invasive cytotypes was very similar to the results for the comparison of native and invasive tetraploids (Table 1). Thus, niche breadth for large-scale vegetation structure (increased) and local-scale abiotic factors (decreased) differed significantly from the combined niche of the diploids and tetraploids in the native range but in contrasting directions.

The geo-cytotypes did not differ in the number of different habitat types and landscape classes in which they occurred (Tables 3 and 4). Nevertheless, frequency of occurrence within major habitat types (forests, grasslands, ruderal sites, and along shores/rivers) differed significantly $\left(\chi_{6}^{2}=17.082, P=0.009\right.$; Table 3$)$. The contrast between diploid and tetraploid populations 
TABLE 1. Outlying mean index (OMI) analyses for niche shifts and differences in niche breadth (ecological tolerance) along climate, vegetation structure, and local abiotic gradients for Centaurea maculosa Lam. in Europe and North America.

\begin{tabular}{|c|c|c|c|c|c|c|}
\hline \multirow[b]{2}{*}{ Variable } & \multicolumn{3}{|c|}{ Niche optimum } & \multicolumn{3}{|c|}{ Niche breadth } \\
\hline & $\begin{array}{l}\text { EU vs. } \\
\text { NA }^{\mathrm{A}}\end{array}$ & $\begin{array}{c}2 x \mathrm{EU} \text { vs. } \\
4 x \mathrm{EU}^{\mathrm{B}}\end{array}$ & $\begin{array}{l}4 x \mathrm{EU} \text { vs. } \\
4 x \mathrm{NA}^{\mathrm{B}}\end{array}$ & $\begin{array}{l}\text { EU vs. } \\
\text { NA }^{\mathrm{A}}\end{array}$ & $\begin{array}{c}2 x \mathrm{EU} \text { vs. } \\
4 x \mathrm{EU}^{\mathrm{B}}\end{array}$ & $\begin{array}{l}4 x \mathrm{EU}_{\mathrm{ES}} \text { v. } \\
4 x \mathrm{NA}^{\mathrm{B}}\end{array}$ \\
\hline \multicolumn{7}{|l|}{ Climate (large scale, $N=141$ ) } \\
\hline $\begin{array}{l}\text { Area } \\
\text { Axis } 1 \dagger\left(100 \%,{ }^{\mathrm{A}} 81 \%^{\mathrm{B}}\right) \\
\text { Axis } 2 \ddagger\left(0 \%,{ }^{A} 19 \%^{\mathrm{B}}\right)\end{array}$ & $\begin{array}{l}\mathbf{0 . 0 0 1} \\
\mathbf{0 . 0 0 1} \\
\mathrm{NR}\end{array}$ & $\begin{array}{c}0.099 \\
\text { NS } \\
\text { 0.001 } \downarrow\end{array}$ & $\begin{array}{l}0.012 \\
0.001 \rightarrow \\
0.001 \uparrow\end{array}$ & $\begin{array}{l}\text { NS } \\
\text { NS } \\
\text { NR }\end{array}$ & $\begin{array}{l}\text { NS } \\
\text { NS } \\
\text { NS }\end{array}$ & $\begin{array}{l}\text { NS } \\
\text { NS } \\
\text { NS }\end{array}$ \\
\hline \multicolumn{7}{|c|}{ Vegetation (large scale, $N=140$ ) } \\
\hline $\begin{array}{l}\text { Area } \\
\text { Axis } 1 \S\left(99 \%,{ }^{\mathrm{A}} 97 \%^{\mathrm{B}}\right) \\
\text { Axis } 2 \|\left(1 \%,{ }^{\mathrm{A}} 3 \%^{\mathrm{B}}\right)\end{array}$ & $\begin{array}{l}\mathbf{0 . 0 0 1} \\
\mathbf{0 . 0 0 1} \\
\mathrm{NS}\end{array}$ & $\begin{array}{l}\text { NS } \\
\text { NS } \\
\text { NS }\end{array}$ & $\begin{array}{l}\mathbf{0 . 0 2 6} \\
\mathbf{0 . 0 1 3} \\
\mathrm{NS}\end{array} \rightarrow$ & $\begin{array}{c}\mathbf{0 . 0 0 2}< \\
\mathbf{0 . 0 0 2}< \\
\text { NS }\end{array}$ & $\begin{array}{l}0.098< \\
\text { NS } \\
\text { NS }\end{array}$ & $\begin{array}{c}\text { NS } \\
\mathbf{0 . 0 3 2} \\
\text { NS }\end{array}$ \\
\hline \multicolumn{7}{|l|}{ Abiotic (local scale, $N=73$ ) } \\
\hline $\begin{array}{l}\text { Area } \\
\text { Axis } 1-\left(100 \%,{ }^{\mathrm{A}} 85 \%^{\mathrm{B}}\right) \\
\text { Axis } 2 \#\left(0 \%,{ }^{\mathrm{A}} 15 \%^{\mathrm{B}}\right)\end{array}$ & $\begin{array}{l}\mathbf{0 . 0 0 2} \\
\mathbf{0 . 0 0 1} \\
\mathrm{NR}\end{array} \rightarrow$ & $\begin{array}{l}\text { NS } \\
\text { NS } \\
\mathbf{0 . 0 1 7} \downarrow\end{array}$ & $\begin{array}{l}\mathbf{0 . 0 3 9} \\
\mathbf{0 . 0 2 4} \rightarrow \\
0.064 \uparrow\end{array}$ & $\begin{array}{c}0.044> \\
0.010> \\
\text { NR }\end{array}$ & $\begin{array}{c}\text { NS } \\
\text { NS } \\
0.070<\end{array}$ & $\begin{array}{l}0.004 \\
\text { NS } \\
0.004>\end{array}$ \\
\hline \multicolumn{7}{|c|}{ Vegetation (local scale, $N=80$ ) } \\
\hline $\begin{array}{l}\text { Area } \\
\text { Axis } 1 \dagger \dagger\left(100 \%{ }^{\mathrm{A}} 93 \%^{\mathrm{B}}\right) \\
\text { Axis } 2 \|\left(0 \%,{ }^{\mathrm{A}} 7 \%^{\mathrm{B}}\right)\end{array}$ & $\begin{array}{l}\mathbf{0 . 0 0 1} \\
\mathbf{0 . 0 0 1} \\
\mathrm{NR}\end{array}$ & $\begin{array}{l}\text { NS } \\
\text { NS } \\
\text { NS }\end{array}$ & $\begin{array}{l}\mathbf{0 . 0 0 2} \\
\mathbf{0 . 0 0 1} \\
\mathrm{NS}\end{array}$ & $\begin{array}{l}\text { NS } \\
\text { NS } \\
\text { NR }\end{array}$ & $\begin{array}{l}\text { NS } \\
\text { NS } \\
\text { NS }\end{array}$ & $\begin{array}{l}\text { NS } \\
\text { NS } \\
\text { NS }\end{array}$ \\
\hline
\end{tabular}

Notes: The direction of niche shifts along axes is indicated with arrows, and increasing/decreasing of niche breadth with $>/<$ symbols; boldface indicates statistically significant differences at $P<0.05$; NS, not significant; NR, not relevant. The OMI analyses were performed separately, either for the contrast between ranges (denoted by superscripted "A"; EU, Europe; NA, North America) or for the contrasts among geo-cytotypes (denoted by superscripted "B"; $2 x$, diploid; $4 x$, tetraploid). Significance of niche differences was assessed with permutation tests, either on the 2-D area of OMI axis 1 and 2 (ellipse area and centroids, differences were weighted by the axis inertia) or on the niche projections on each OMI axis (niche centroids or variance of means). No values are given for axes inertia $<0.5 \%$ (indicated by NR); inertia values are given in parentheses in the body of the table. Correlations of variables with a given axis are given in the following footnotes (for variable descriptions see Methods and Appendix B).

$\dagger^{\mathrm{A}}$ AET/PET (-0.68), PET (0.62), TMIN (-0.46), TMAX (0.37), GDD (-0.32), STD_PREC (0.25), PREC (0.04). ${ }^{\mathrm{B}}$ AET/PET $(-0.66)$, PET (0.64), TMAX (0.40), TMIN (-0.38), STD PREC $(0.30)$, GDD $(-0.25)$, $\overline{\text { PREC }}(0.06)$.

$+{ }^{\mathrm{B}}$ GDD $(-0.38)$, TMAX $(-0.26)$, TMIN $(-0.23)$, PET $(-0.21)$, PREC $(0.07)$, AET/PET $(-0.05)$, STD PREC (0.04).

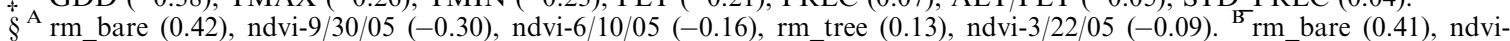
9/30/05 (-0.24), ndvi-6/10/05 (-0.18), rm_tree (0.12), ndvi-3/22/05 (-0.02).

$\|$ No significant niche shifts or changes in niche breadth were shown along these axes.

- ${ }^{\mathrm{A}} \mathrm{CaCO}_{3}(-0.40)$, chroma $(0.34), \mathrm{pH}(-0.25)$, slope $(-0.23)$, value $(-0.14)$, clay $(-0.04) .{ }^{\mathrm{B}}$ chroma $(0.40), \mathrm{CaCO}_{3}(-0.37)$, slope $(-0.29), \mathrm{pH}(-0.26)$, value $(-0.12)$, clay $(-0.05)$.

\# ${ }^{\mathrm{B}} \mathrm{CaCO}_{3}(-0.20)$, chroma $(-0.17)$, value $(-0.10)$, slope $(0.08), \mathrm{pH}(-0.01)$, clay $(-0.01)$.

$\dagger^{\mathrm{A}}$ gr_height (0.45), fo_height (0.38), forbs $(-0.32)$, bare (0.19), grass $(-0.13){ }^{\mathrm{B}}{ }^{\text {gr_height }}(0.46)$, fo_height $(0.36)$, forbs ( -0.35$)$, bare $(0 . \overline{18})$, grass $(-0.09)$.

in the native range was significant $\left(\chi_{3}^{2}=8.804, P=\right.$ 0.035 ), while tetraploid populations between ranges did not differ significantly $\left(\chi_{3}^{2}=2.837, P=0.418\right)$. Diploid populations occurred predominantly in grasslands, especially natural dry meadows, while tetraploid populations had a more balanced occurrence among the different habitat types. The occurrence in ruderal sites was very similar for all geo-cytotypes while the occurrence in open forest habitats tends to increase in the introduced range. Using remote sensing data, we found that the three geo-cytotypes also differed significantly in their frequency among five different land cover classes $\left(\chi_{8}^{2}=22.190, P=0.004\right.$; Table 4$)$. Again, the contrast between native diploid and tetraploid populations was significant $\left(\chi_{4}^{2}=9.569, P=0.047\right)$, while tetraploid populations between ranges did not differ significantly $\left(\chi_{4}^{2}=2.814, P=0.589\right)$. In the native range, populations in southern France were most strongly associated with open forests or woodland habitats. Excluding these populations from the analyses, and thus accounting for ambiguous $4 x$ DNA ploidy-level esti- mates, tetraploid cytotypes also tended to differ between ranges (cf. Appendix C). We did not find any difference in frequency occurrence of geo-cytotypes in habitats with low, medium, or high anthropogenic disturbance $\left(\chi_{4}^{2}=1.542, P=0.819\right)$.

\section{Differences in population traits between geo-cytotypes}

Data from our field survey revealed significant differences between native and invasive populations for some traits, with plants from the introduced range exhibiting more stems, an increased proportion of polycarpy (indicated by post-reproductive emergence of lateral buds/shoots), and more damage by internal root feeders (Table 5). Invasive populations also tended to cover larger areas and to have higher densities of large rosettes and flowering plants (Table 5). In Europe, tetraploid populations, compared to their diploid conspecifics, showed a significant increase in the number of stems per plant and tended to have higher proportions of polycarpic plants (Table 5). Moreover, invasive tetraploids had a significantly higher proportion of 
polycarpic plants, had lower damage levels of external root feeders, and covered larger areas than native tetraploids (Table 5). A two-way factorial ANOVA with stem number as the response variable and geocytotype (three levels, $2 x \mathrm{EU}, 4 x \mathrm{EU}$, and $4 x \mathrm{NA}$ ) and anthropogenic disturbance (three levels, low, medium, high) as explanatory factors gave significant results for geo-cytotype $\left(F_{2,34}=5.103, P<0.001\right)$ and the interaction term $\left(F_{4,34}=4.095, P=0.008\right)$. In highly disturbed habitats (e.g., roadsides), $4 x \mathrm{NA}$ geo-cytotypes had increased number of stems $(9.0 \pm 1.2$ stems $)$ compared with $4 x \mathrm{EU}(2.7 \pm 1.3$ stems $)$ and $2 x \mathrm{EU}(1.2$ \pm 1.3 stems), while in habitats with low (1.3-3.8 stems) or intermediate disturbance (1.5-3.6 stems), geo-cytotypes varied little in stem number.

\section{DisCUSSION}

This study represents the first global assessment of the geographical distribution of ploidy cytotypes in $C$. maculosa s.l. We report a profound shift in the ratio of the two ploidy types between the native (Europe) and the introduced (North America) ranges. Furthermore, our study suggests that, as previously hypothesized, both ploidy types of $C$. maculosa were introduced into North America, but tetraploids became the dominant cytotype during the invasion process. Two contrasting, but mutually nonexclusive hypotheses dominate the literature on plant invasion (Müller-Schärer and Steinger 2004). The first assumes that specific trait combinations preadapt species to become good invaders ("preadaptation hypothesis"), whereas the second postulates successful invasion as the outcome of rapid evolutionary change in the new habitat ("post-invasion evolution hypothesis"). Our results provide support for both hypotheses: The tetraploid cytotype of C. maculosa comprises genotypes that possibly were preadapted to ecological conditions in the introduced range (1) through increased tolerance to drier conditions and (2) through changes in functional traits, especially increased polycarpy, providing them with an advantage over diploids during the invasion process. Additionally, tetraploids may have further evolved through directional selection in the introduced range, as indicated by the shift in niche optima and climatic differences between ranges, suggesting rapid post-invasion evolution (Fig. 2 and Table 2; Broennimann et al. 2007). It must be stressed, however, that our study cannot exclude the possibility that other processes (e.g., founder events) were responsible for the observed shift in cytotype frequency.

As reported by Broennimann et al. (2007), $C$. maculosa shows a clear shift in the climatic niche space between the native and introduced ranges. Our findings confirmed this shift using various environmental gradients at different scales (Table 1). Interestingly, we additionally demonstrate that such niche shifts also occurred between geo-cytotypes, thus between diploid and tetraploids in the native range and tetraploids

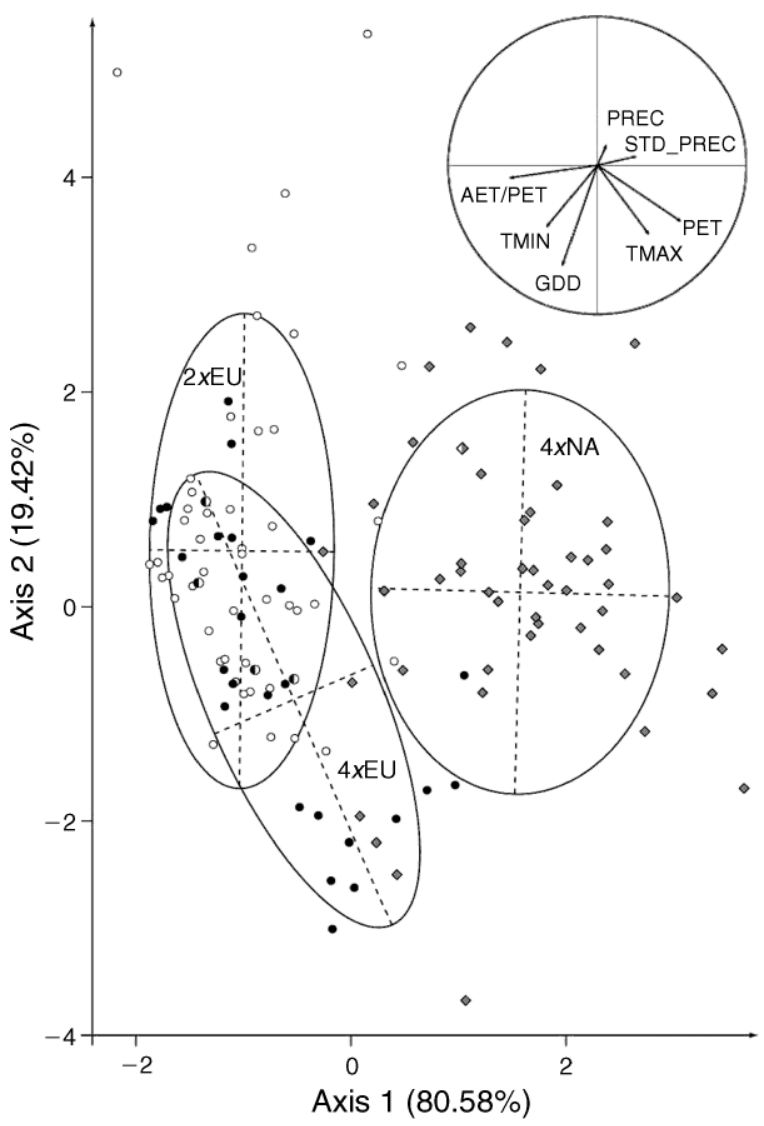

FIG. 2. Outlying mean index analysis (OMI) of 141 Centaurea maculosa populations in Europe (EU) and North America (NA) divided into three geo-cytotypes. The enclosed correlation circle $(r=1)$ shows the included climatic variables and their correlation with the OMI axes. Axes inertia are given in brackets. For details on ellipses (1.5 SD) see Methods. Symbols are as in Fig. 1. Climatic variable abbreviations are: PET, potential evapotranspiration; AET/PET, ratio of actual to potential evapotranspiration; PREC, annual precipitation; STD PREC, annual variation in precipitation; TMIN, minimum temperature of the coldest months; TMAX, maximum temperature of the warmest months; GDD, growing degreedays, defined as the sum of mean daily temperatures above $5^{\circ} \mathrm{C}$.

between ranges. Furthermore, a few climatic parameters (in particular potential evapotranspiration) unravel a sequential shift between cytotypes in the native range and tetraploids between ranges toward drier conditions (Table 2). Niche breadth of tetraploids in the native range increased for some of the gradients compared to diploids and it further increased for the large-scale vegetation gradient in the introduced range, but decreased for local-scale abiotic conditions (Table 1). Diploids and tetraploids did not, however, differ in the number of habitats they occupy, although tetraploids have a more balanced occurrence across the different habitat types and land cover classes (Tables 3 and 4). Thus, the pattern for niche breadth between cytotypes in the native range partly supports the hypothesis that polyploids may have increased ecological tolerance. 
TABLE 2. Results of logistic regression models of contrasts between geo-cytotypes of Centaurea maculosa Lam. in Europe and North America and single climatic variables.

\begin{tabular}{|c|c|c|c|c|c|c|c|c|}
\hline \multirow[b]{2}{*}{ Variable } & \multicolumn{3}{|c|}{$2 x \mathrm{EU}$ vs. $4 x \mathrm{EU}$} & \multicolumn{3}{|c|}{$4 x \mathrm{EU}$ vs. $4 x \mathrm{NA}$} & \multicolumn{2}{|c|}{$2 x 4 x$ EU to $4 x$ EUNA $\dagger$} \\
\hline & AUC & $\begin{array}{c}\text { Shift } \\
\text { direction }\end{array}$ & $\begin{array}{c}\text { Percentage correct } \\
(2 x \mathrm{EU}, 4 x \mathrm{EU})\end{array}$ & AUC & $\begin{array}{c}\text { Shift } \\
\text { direction }\end{array}$ & $\begin{array}{c}\text { Percentage correct } \\
(4 x \mathrm{EU}, 4 x \mathrm{NA})\end{array}$ & AUC & $\begin{array}{c}\text { Percentage correct } \\
(4 x \mathrm{EU}, 4 x \mathrm{NA})\end{array}$ \\
\hline AET/PET & NS & & 95,4 & $0.88 * * *$ & $\leftarrow$ & 75,78 & $0.87^{*}$ & 85,60 \\
\hline GDD & $0.76^{* *}$ & $\rightarrow$ & 85,46 & $0.85^{* * *} *$ & $\leftarrow$ & 58,86 & NS & 42,10 \\
\hline PET & $0.73 * *$ & $\rightarrow$ & 92,40 & $0.70^{*}$ & $\rightarrow$ & 60,83 & $0.71^{*}$ & 49,90 \\
\hline PREC & NS & & 95,8 & NS & & 5,85 & NS & 92,21 \\
\hline STD PREC & NS & & 98,1 & NS & & 14,83 & NS & 89,23 \\
\hline TMÄX & $0.76^{* * *}$ & $\rightarrow$ & 87,48 & NS & & 20,88 & NS & 40,74 \\
\hline TMIN & NS & & 97,5 & $0.79 * *$ & $\leftarrow$ & 52,81 & NS & 68,4 \\
\hline
\end{tabular}

Notes: Model accuracy is reported as mean area under the curve (AUC; on test data), and $P$ values were calculated from 999 models run on randomly split data sets ( $70 \%$ for training, $30 \%$ for testing). In addition, we report the conditional probability of correctly predicted geo-cytotypes. Arrows indicate the shift direction along the gradient. For variable descriptions see Methods and Appendix B. Other abbreviations are: EU, Europe; NA, North America; $2 x$, diploid; $4 x$, tetraploid. Probabilities for AUC values: $* P<0.05 ; * * P<0.01 ; * * P<0.001 ; \mathrm{NS}$, not significant.

$\dagger$ Models were calibrated on cytotypes in the native range and subsequently applied to tetraploids in both ranges to predict niche shifts for the invasive cytotype along the single environmental gradients.

Answering our first two questions, the cytotypes did differ in their niche breadth and optima in the native range, even though a large niche overlap was observed. Furthermore, the niche of the tetraploid cytotype further shifted in the introduced range and differed significantly from the combined niche of diploids and polyploids in the native range (Table 1 and Fig. 2).

The observed niche differences between the two ranges provide support for the idea outlined in the introduction that polyploidization in C. maculosa may have led to increased tolerance to warmer and drier conditions. Preadaptation to such altered environmental conditions in the introduced range may at least partly have increased the invasion success of polyploids. This view finds support in the introduction history of $C$. maculosa, a species introduced at least a few if not multiple times into North America (Hufbauer and Sforza 2008) and at least in two different areas (Roché et al. 1986). The earliest report dates to 1893 for Victoria, British Columbia, Canada, from where it subsequently spread into the coastal areas of British Columbia and Washington, USA. The species, however, appears to have spread into Washington in greater numbers from the east and was abundant in Montana

TABLE 3. Occurrence (\%) of populations of Centaurea maculosa Lam. in major habitat types in Europe (EU) and North America (NA) derived from field data.

\begin{tabular}{lccccc}
\hline \hline \multirow{2}{*}{$\begin{array}{c}\text { Geo- } \\
\text { cytotype }\end{array}$} & \multicolumn{4}{c}{ Habitat type } & \\
\cline { 2 - 5 } & Forest & Grassland & Ruderal & Waterside & $N$ \\
\hline $2 x$ EU & 2 & 65 & 31 & 2 & 45 \\
$4 x$ EU & 14 & 43 & 29 & 14 & 28 \\
$4 x$ NA & 27 & 30 & 36 & 7 & 30
\end{tabular}

Notes: Geo-cytotypes are defined as native diploids ( $2 x \mathrm{EU})$, native tetraploids $(4 x \mathrm{EU})$, and invasive tetraploids $(4 x \mathrm{NA})$. Habitat types are: forest, open forest habitats or forest edges; grassland, meadows, pastures, or seminatural grasslands; ruderal, mainly roadsides, rarely other wasteland; waterside, along rivers, lakes, or seashores. $N=$ no. populations. before it became common in eastern Washington (Roché et al. 1986). This strongly suggests that C. maculosa also was introduced to Montana, probably as alfalfa seed contaminants. Today, Montana suffers from large infestations by this noxious invader and thus may be regarded as one of today's core areas of C. maculosa invasion. Compared to the native range, the climatic conditions are drier and warmer in these areas (Broennimann et al. 2007). Hence, after introduction the species was exposed to different climatic conditions and this may have given tetraploids an advantage, as they were better adapted to these conditions. However, as stressed above strong founder effect provides an alternative explanation for the pronounced shift in cytotype frequency (Kliber and Eckert 2005). Molecular marker studies including a large set of populations of both ranges are needed to further disentangle these processes.

Although we found evidence for potential preadaptation of tetraploids through increased tolerance to environmental conditions in the introduced range, changes in life-history traits may also be implicated in the invasion success of tetraploids. In agreement with earlier reports, our field study revealed that tetraploid

TABLE 4. Occurrence (\%) of populations of Centaurea maculosa Lam. in major land cover classes in Europe (EU) and North America (NA) derived from remote sensing data.

\begin{tabular}{ccccccc}
\hline \hline \multirow{2}{*}{$\begin{array}{c}\text { Geo- } \\
\text { cytotype }\end{array}$} & \multicolumn{5}{c}{ Land cover classes } \\
\cline { 2 - 5 } & Forest & Woodland & Grassland & Cropland & Urban & $N$ \\
\hline $2 x$ EU & 10 & 23 & 4 & 60 & 4 & 52 \\
$4 x$ EU & 11 & 43 & 14 & 30 & 3 & 37 \\
$4 x$ NA & 17 & 41 & 17 & 17 & 7 & 46
\end{tabular}

Notes: Geo-cytotypes are defined as native diploids ( $2 x \mathrm{EU})$, native tetraploids $(4 x \mathrm{EU})$, and invasive tetraploids $(4 x \mathrm{NA})$; EU, Europe; NA, North America. The woodland land cover class includes mainly woodland and wooded grassland, rarely shrub land; the urban land cover class includes urban and builtup areas. $N=$ no. populations. 
TABLE 5. Differences in population traits of Centaurea maculosa Lam. between ranges in Europe (EU) and North America (NA) and between geo-cytotypes.

\begin{tabular}{|c|c|c|c|c|c|c|c|c|c|}
\hline \multirow[b]{2}{*}{ Trait } & \multicolumn{3}{|c|}{ EU, NA } & \multicolumn{3}{|c|}{$2 x \mathrm{EU}, 4 x \mathrm{EU}$} & \multicolumn{3}{|c|}{$4 x \mathrm{EU}, 4 x \mathrm{NA}$} \\
\hline & $N$ & Median & $P$ & $N$ & Median & $P$ & $N$ & Median & $P$ \\
\hline $\begin{array}{l}\text { Population density (plants } / \mathrm{m}^{2} \text { ) } \\
\text { Small rosettes (SR) } \\
\text { Large rosettes (LR) } \\
\text { Flowering plants (FP) }\end{array}$ & $\begin{array}{l}25,14 \\
25,14 \\
25,14 \\
25,14\end{array}$ & $\begin{array}{l}6.96,15.60 \\
1.55,1.25 \\
0.50,3.48 \\
3.95,9.43\end{array}$ & $\begin{array}{l}\text { NS } \\
\text { NS } \\
0.079 \\
0.104\end{array}$ & $\begin{array}{l}14,11 \\
14,11 \\
14,11 \\
14,11\end{array}$ & $\begin{array}{l}7.23,5.65 \\
2.13,0.45 \\
0.55,0.15 \\
4.00,3.45\end{array}$ & $\begin{array}{l}\text { NS } \\
\text { NS } \\
\text { NS } \\
\text { NS }\end{array}$ & $\begin{array}{l}11,14 \\
11,14 \\
11,14 \\
11,14\end{array}$ & $\begin{array}{l}5.65,15.60 \\
0.45,1.25 \\
0.15,3.48 \\
3.45,9.43\end{array}$ & $\begin{array}{l}\text { NS } \\
\text { NS } \\
\text { NS } \\
\text { NS }\end{array}$ \\
\hline $\begin{array}{l}\text { Proportion of SR (SR/[SR }+\mathrm{LR}+\mathrm{FP}]) \\
\text { Proportion of FP (FP/[SR }+\mathrm{LR}+\mathrm{FP}]) \\
\text { Area covered (area classes) } \\
\text { Mean height of flowering plants }(\mathrm{cm}) \\
\text { Mean diameter of flowering plants }(\mathrm{cm}) \\
\text { Number of stems } \\
\text { Polycarpy (new lateral buds/shoots) }\end{array}$ & $\begin{array}{l}25,14 \\
25,14 \\
82,29 \\
25,18 \\
25,18 \\
25,18 \\
25,21\end{array}$ & $\begin{array}{l}0.26,0.12 \\
0.59,0.61 \\
3.5,4.0 \\
58,54 \\
22,29 \\
1.88,5.47 \\
0,1\end{array}$ & $\begin{array}{l}\text { NS } \\
\text { NS } \\
0.102 \\
\text { NS } \\
\text { NS } \\
\mathbf{0 . 0 0 2} \\
\mathbf{0 . 0 0 0}\end{array}$ & $\begin{array}{l}14,11 \\
14,11 \\
48,34 \\
14,11 \\
14,11 \\
14,11 \\
14,11\end{array}$ & $\begin{array}{l}0.30,0.16 \\
0.58,0.74 \\
4.0,2.5 \\
62,46 \\
22,22 \\
1.18,3.14 \\
0,0\end{array}$ & $\begin{array}{l}\text { NS } \\
\text { NS } \\
\text { NS } \\
\text { NS } \\
\text { NS } \\
\mathbf{0 . 0 0 0} \\
0.074\end{array}$ & $\begin{array}{l}11,14 \\
11,14 \\
34,29 \\
11,18 \\
11,18 \\
11,18 \\
11,21\end{array}$ & $\begin{array}{l}0.16,0.12 \\
0.74,0.61 \\
2.5,4.0 \\
46,54 \\
22,29 \\
3.14,5.47 \\
\quad 0,1\end{array}$ & $\begin{array}{c}\text { NS } \\
\text { NS } \\
\mathbf{0 . 0 2 6} \\
\text { NS } \\
\text { NS } \\
\text { NS } \\
\mathbf{0 . 0 0 0}\end{array}$ \\
\hline $\begin{array}{l}\text { Total root herbivore damages } \\
\text { Only external } \\
\text { Only internal } \\
\text { Only collar }\end{array}$ & $\begin{array}{l}25,14 \\
25,14 \\
25,14 \\
25,14\end{array}$ & $\begin{array}{l}0.12,0.17 \\
0.04,0.00 \\
0.10,0.30 \\
0.19,0.20\end{array}$ & $\begin{array}{l}\text { NS } \\
0.084 \\
\mathbf{0 . 0 2 3} \\
\text { NS }\end{array}$ & $\begin{array}{l}14,11 \\
14,11 \\
14,11 \\
14,11\end{array}$ & $\begin{array}{l}0.06,0.19 \\
0.01,0.08 \\
0.05,0.13 \\
0.15,0.31\end{array}$ & $\begin{array}{l}\text { NS } \\
\text { NS } \\
\text { NS } \\
\text { NS }\end{array}$ & $\begin{array}{l}11,14 \\
11,14 \\
11,14 \\
11,14\end{array}$ & $\begin{array}{l}0.19,0.17 \\
0.08,0.00 \\
0.13,0.30 \\
0.31,0.20\end{array}$ & $\begin{array}{l}\text { NS } \\
\mathbf{0 . 0 3 3} \\
\text { NS } \\
\text { NS }\end{array}$ \\
\hline
\end{tabular}

Notes: Significance of the differences was determined with Mann-Whitney $U$ tests; $P$ values were corrected for multiple comparisons. Boldface indicates statistically significant differences at $P<0.05$; NS, not significant. Geo-cytotypes are defined as native diploids $(2 x \mathrm{EU})$, native tetraploids $(4 x \mathrm{EU})$, and invasive tetraploids $(4 x \mathrm{NA}) . N=$ no. populations.

populations consist of plants with more stems and a higher relative frequency of polycarpy than diploid populations (Müller 1989a, Ochsmann 2001). Our data suggest that this relationship is only partial, and thus, polycarpy and polyploidy are not strictly linked. Nevertheless, it implies that tetraploids have a higher tendency for a long-lived, polycarpic life-form, which is most probably genetically determined. In agreement with these findings, an older age structure for tetraploid than for diploid populations was recently found in Europe (C. Bollig, personal communication) and North American plants were reported to live up to $9 \mathrm{yr}$ (Boggs and Story 1987). Monocarpic plants of C. maculosa in general flower in the second year, while polycarpic plants flower in the first year and thus have a shorter juvenile period (Müller 1989a). Stem number and polycarpy was highest in the introduced range, which suggests selection favoring polycarpy and thus, earlier and repeated reproduction during establishment in the introduced range free of natural enemies. This confirms our expectations, as outlined in the introduction, and predictions of the evolution of increased competitive ability (EICA) hypothesis (Blossey and Nötzold 1995).

Our field surveys of root herbivory revealed different patterns for external and internal root feeders. In the native range we found higher damage at the external part of the root while internal damage was higher in the introduced range. Generalist arthropod herbivores are mainly feeding externally, while specialist arthropod herbivores are internal feeders (Strong et al. 1984). The high level of internal root herbivory in the introduced range may be the result of the large-scale biocontrol effort against $C$. maculosa (Müller-Schärer and Schroeder 1993). Nevertheless, up to now C. maculosa remains an uncontrollable invasive species despite considerable biocontrol efforts over the past 46 years and recent observations of population declines at some sites (Story et al. 2006). This observation, however, does not exclude the possibility that the initial absence (for the first 70 years) of specialized natural enemies in the introduced range may have influenced the observed shift in cytotype occurrence. It seems reasonable to hypothesize that the invasion success of tetraploids was enforced by traits linked to this cytotype, such as the perennial, polycarpic life cycle with its earlier and repeated seed production, possibly providing tetraploids with an advantage under release from natural enemies in the introduced range.

The results of our field study provide support for both preadaptation and post-invasion evolution as possible explanations for the increased invasion success of tetraploid $C$. maculosa, but experimental studies are required to confirm our findings and to disentangle alternative mechanisms (e.g., founder events). We especially note that niche analyses based on field data can only provide information on the realized niche and will approach the fundamental niche only in cases in which dispersal or biotic interactions do not play an important role. It therefore remains to be shown to what extent the observed niche shift is due to physiological differences among geo-cytotypes or alterations in the realized niche caused by biotic interactions. Common garden experiments will enable us to asses whether the observed increase in polycarpy or stem number of North American tetraploids under field conditions is indeed genetically based or simply due to continent-specific environmental effects on plant phenotypes.

Interestingly, the populations located in southern France showed not only anomalies in DNA ploidy but were also different in their position in the climatic niche space, occurring under conditions with more mean daily temperatures above $5^{\circ} \mathrm{C}$ (growing degree-days). The 
difficult taxonomy of $C$. maculosa s.l. may explain this observation (Hufbauer and Sforza 2008). Our study therefore highlights that morphological and molecular studies that include many plants from various populations of the native and introduced ranges are needed to resolve the taxonomic problems in this group and the origin of the introduced populations. Hybridization is commonly observed and a possible hybrid origin of tetraploids as well as the mode of polyploidization (allovs. auto-polyploidization) needs additional clarification. Hybridization is increasingly recognized as an additional mechanism promoting the invasiveness in plants (Ellstrand and Schierenbeck 2000). In line with this, polyploid populations that arose through allopolyploidization may maintain most of their genetic variation in spite of inbreeding and bottlenecks because each individual carries a large fraction of the populations gene pool in the form of fixed heterozygosity, while populations of outcrossing diploids typically become genetically depauperate when exposed to inbreeding and bottlenecks (Brochmann et al. 2004). Polyploids are thus given a further advantage, especially when dispersed over long distances by humans and introduced to new ranges. In addition to preadaptation to the altered ecological setup (climate or lack of natural enemies), hybridization may provide a further explanation for the dominance of the tetraploid cytotype in the introduced range.

For species showing ploidy variation, our study strongly advocates considering ploidy level as a further important factor promoting invasions. Ecological differences between cytotypes are increasingly recognized, even under autopolyploidy, and different ploidy types may thus be considered as distinct biological entities (Soltis et al. 2007).

\section{ACKNOWLEDGMENTS}

We thank Aurélie Thébault, Olga Korniyenko, Patrick Häfliger, Eric M. Coombs, Jim Story, and Gilles Thelen for help in the field; Anne-Catherine Pasche and Amélie Fragnière for laboratory assistance; all collectors (see appendix A) for sending seed material; and two anonymous reviewers for their helpful comments. U. A. Treier especially thanks Thomas Fabbro and Jens-Christian Svenning for fruitful discussions, Robert Ricklefs for very helpful suggestions to improve the manuscript, and Henrik Balslev for his invitation to work at the University of Aarhus. This project was funded by the National Centre of Competence in Research (NCCR) Plant Survival, research program of the Swiss National Science Foundation.

\section{Literature Cited}

Bancheva, S., and J. Greilhuber. 2006. Genome size in Bulgarian Centaurea s.l. (Asteraceae). Plant Systematics and Evolution 257:95-117.

Blossey, B., and R. Nötzold. 1995. Evolution of increased competitive ability in invasive nonindigenous plants: a hypothesis. Journal of Ecology 83:887-889.

Boggs, K. W., and J. M. Story. 1987. The population age structure of spotted knapweed (Centaurea maculosa) in Montana. Weed Science 35:194-198.

Böhle, U. R., H. H. Hilger, and W. F. Martin. 1996. Island colonization and evolution of the insular woody habit in Echium L. (Boraginaceae). Proceedings of the National Academy of Sciences (USA) 93:11740-11745.
Borgen, L., and U.-M. Hultgård. 2003. Parnassia palustris: a genetically diverse species in Scandinavia. Botanical Journal of the Linnean Society 142:347-372.

Brochmann, C., A. K. Brysting, I. G. Alsos, L. Borgen, H. H. Grundt, A. C. Scheen, and R. Elven. 2004. Polyploidy in arctic plants. Biological Journal of the Linnean Society 82: 521-536.

Broennimann, O., U. A. Treier, H. Müller-Schärer, W. Thuiller, A. T. Peterson, and A. Guisan. 2007. Evidence of climatic niche shift during biological invasion. Ecology Letters 10:701-709.

Callaway, R. M., and W. M. Ridenour. 2004. Novel weapons: invasive success and the evolution of increased competitive ability. Frontiers in Ecology and the Environment 2:436-443.

Doledec, S., D. Chessel, and C. Gimaret-Carpentier. 2000. Niche separation in community analysis: a new method. Ecology 81:2914-2927.

Dray, S., and A. Dufour. 2007. The ade4 package: Implementing the duality diagram for ecologists. Journal of Statistical Software 22:1-20.

Ellstrand, N. C., and K. A. Schierenbeck. 2000. Hybridization as a stimulus for the evolution of invasiveness in plants? Proceedings of the National Academy of Sciences (USA) 97: 7043-7050.

Felber-Girard, M., F. Felber, and A. Buttler. 1996. Habitat differentiation in a narrow hybrid zone between diploid and tetraploid Anthoxanthum alpinum. New Phytologist 133:531540.

Fielding, A. H., and J. F. Bell. 1997. A review of methods for the assessment of prediction errors in conservation presence/absence models. Environmental Conservation 24:38-49.

Gauthier, P., R. Lumaret, and A. Bedecarrats. 1998. Genetic variation and gene flow in Alpine diploid and tetraploid populations of Lotus (L. alpinus (DC) Schleicher $L$. corniculatus L). I. Insights from morphological and allozyme markers. Heredity 80:683-693.

Hagerup, O. 1933. Studies on polyploid ecotypes in Vaccinium uliginosum L. Hereditas 18:122-128.

Hansen, M. C., R. S. Defries, J. R. G. Townshend, and R. Sohlberg. 2000. Global land cover classification at $1 \mathrm{~km}$ spatial resolution using a classification tree approach. International Journal of Remote Sensing 21:1331-1364.

Hosmer, D. W., and S. Lemeshow. 2000. Applied logistic regression. Second edition. John Wiley and Sons, Hoboken, New Jersey, USA.

Hufbauer, R. A., and R. Sforza. 2008. Multiple introductions of two invasive Centaurea taxa inferred from cpDNA haplotypes. Diversity and Distributions 14:252-261.

Keane, R. M., and M. J. Crawley. 2002. Exotic plant invasions and the enemy release hypothesis. Trends in Ecology and Evolution 17:164-170.

Kliber, A., and C. G. Eckert. 2005. Interaction between founder effect and selection during biological invasion in an aquatic plant. Evolution 59:1900-1913.

Klinkhamer, P. G. L., T. Kubo, and Y. Iwasa. 1997. Herbivores and the evolution of the semelparous perennial life-history of plants. Journal of Evolutionary Biology 10:529-550.

Lawton, J. H., and D. Schroder. 1977. Effects of pant type, size of geographical range and taxonomic isolation on number of insect species associated with British plants. Nature 265:137140.

Levin, D. A. 1975. Minority cytotype exclusion in local plant populations. Taxon 24:35-43.

Levin, D. A. 2002. The role of chromosomal change in plant evolution. Oxford University Press, New York, New York, USA.

Lowry, E., and S. E. Lester. 2006. The biogeography of plant reproduction: potential determinants of species' range sizes. Journal of Biogeography 33:1975-1982.

Mack, R. N., D. Simberloff, W. M. Lonsdale, H. Evans, M. Clout, and F. A. Bazzaz. 2000. Biotic invasions: causes, 
epidemiology, global consequences, and control. Ecological Applications 10:689-710.

Mosquin, T., and E. Small. 1971. Example of parallel evolution in Epilobium (Onagraceae). Evolution 25:678-682.

Müller, H. 1989a. Growth pattern of diploid and tetraploid spotted knapweed, Centaurea maculosa Lam. (Compositae), and effects of the root-mining moth Agapeta zoegana (L.) (Lep.: Cochylidae). Weed Research 29:103-111.

Müller, H. 1989b. Structural analysis of the phytophagous insect guilds associated with the roots of Centaurea maculosa Lam. C. diffusa Lam., and C. vallesiaca Jordan in Europe: 1. Field observations. Oecologia 78:41-52.

Müller, H., C. S. A. Stinson, K. Marquardt, and D. Schroeder. 1989. The entomofaunas of roots of Centaurea maculosa Lam. C. diffusa Lam., and C. vallesiaca Jordan in Europe: niche separation in space and time. Journal of Applied Entomology 107:83-95.

Müller-Schärer, H., U. Schaffner, and T. Steinger. 2004. Evolution in invasive plants: implications for biological control. Trends in Ecology and Evolution 19:417-422.

Müller-Schärer, H., and D. Schroeder. 1993. The biological control of Centaurea spp. in North America: Do insects solve the problem? Pesticide Science 37:343-353.

Müller-Schärer, H., and T. Steinger. 2004. Predicting evolutionary change in invasive, exotic plants and its consequences for plant-herbivore interactions. Pages 137-162 in L. E. Ehler, R. Sforza, and T. Mateille, editors. Genetics, evolution and biological control. CABI Publishing, Wallingford, UK.

Munsell Color. 1975. Munsell soil color charts. Kollmorgen, Baltimore, Maryland, USA.

New, M., D. Lister, M. Hulme, and I. Makin. 2002. A highresolution data set of surface climate over global land areas. Climate Research 21:1-25.

Ochsmann, J. 1999. Chromosomenzahlen einiger europäischer Centaurea-Sippen (Asteraceae). Haussknechtia 7:59-65.

Ochsmann, J. 2000. Morphologische und molekularsystematische Untersuchungen an der Centaurea stoebe L.-Gruppe (Asteraceae-Cardueae) in Europa. Thesis (Dissertationes Botanicae 324). Georg-August-Universität, Göttingen, Germany.

Ochsmann, J. 2001. On the taxonomy of spotted knapweed (Centaurea stoebe L.). Pages 33-41 in Proceedings of the First International Knapweed Symposium of the Twenty-First Century, Coeur d'Alene, Idaho. U.S. Department of Agriculture. Agricultural Research Service, Albany, California, USA.

Pandit, M. K. 2006. Continuing the search for pattern among rare plants: Are diploid species more likely to be rare? Evolutionary Ecology Research 8:543-552.

Pandit, M. K., H. T. W. Tan, and M. S. Bisht. 2006. Polyploidy in invasive plant species of Singapore. Botanical Journal of the Linnean Society 151:395-403.
Pearce, J., and S. Ferrier. 2000. Evaluating the predictive performance of habitat models developed using logistic regression. Ecological Modelling 133:225-245.

R Development Core Team. 2007. R: A language and environment for statistical computing. R Foundation for Statistical Computing, Vienna, Austria. 〈http://www. R-project.org

Roché, B. F. J., G. L. Piper, and C. J. Talbott. 1986. Knapweeds of Washington. Bulletin EB1393. Washington State University Cooperative Extension Service, Pullman, Washington, USA.

Royal Botanic Garden Edinburgh. 2007. Flora Europaea data set. 〈http://rbg-web2.rbge.org.uk/FE/fe.html

Sokal, R. R., and F. J. Rohlf. 1995. Biometry. Third edition. W. H. Freeman, New York, New York, USA.

Soltis, D. E., and P. S. Soltis. 1989. Genetic consequences of autopolyploidy in Tolmiea (Saxifragacea). Evolution 43:586594.

Soltis, D. E., P. S. Soltis, D. W. Schemske, J. F. Hancock, J. N. Thompson, B. C. Husband, and W. S. Judd. 2007. Autopolyploidy in angiosperms: Have we grossly underestimated the number of species? Taxon 56:13-30.

Stebbins, G. L. 1971. Chromosomal evolution in higher plants. Edward Arnold, London, UK.

Story, J. M., N. W. Callan, J. G. Corn, and L. J. White. 2006. Decline of spotted knapweed density at two sites in western Montana with large populations of the introduced root weevil, Cyphocleonus achates (Fahraeus). Biological Control 38:227-232.

Strong, D. R., J. H. Lawton, and T. R. E. Southwood. 1984. Insects on plants: community patterns and mechanisms. Blackwell Scientific, Oxford, UK.

Stuessy, T. F., H. Weiss-Schneeweiss, and D. J. Keil. 2004. Diploid and polyploid cytotype distribution in Melampodium cinereum and M. leucanthum (Asteraceae, Heliantheae). American Journal of Botany 91:889-898.

Thuiller, W., S. Lavorel, and M. B. Araujo. 2005. Niche properties and geographical extent as predictors of species sensitivity to climate change. Global Ecology and Biogeography $14: 347-357$.

Thuiller, W., S. Lavorel, G. Midgley, S. Lavergne, and T. Rebelo. 2004. Relating plant traits and species distributions along bioclimatic gradients for 88 Leucadendron taxa. Ecology 85:1688-1699.

Van Dijk, P., M. Hartog, and W. Vandelden. 1992. Single cytotype areas in autopolyploid Plantago media L. Biological Journal of the Linnean Society 46:315-331.

Verlaque, R., A. Aboucaya, and A. Fridlender. 2002. Les xénophytes envahissants en France: ecologie, types biologiques et polyploïdie. Botanica Helvetica 112:121-136.

\section{APPENDIX A}

Description of population sites, sampling type, and DNA ploidy level (Ecological Archives E090-089-A1).

\section{APPENDIX B}

Environmental variables used in the analyses (Ecological Archives E090-089-A2).

\section{APPENDIX C}

Results of all analyses computed without the putative $4 x$ southern France populations (Ecological Archives E090-089-A3). 